\title{
Transformation of snow damage and its societal background in recent Japan
}

\author{
NATSUO Numano \\ Shinjo Branch of Snow and Ice Studies, National Research Institute for Earth Science and Disaster Prevention (NIED), \\ Shinjo, Yamagata 996, Japan
}

\section{SUMMARY}

After Japan's rapid economic growth during the past three decades, snow damage characteristics have changed remarkably. Since there has been no considerable change in climatic conditons, the main cause of change is clearly based on social factors. Among many kinds of snow damage, the most serious are those which do any injury to the human body (human body snow damage, HBSD). This paper examines the time-series change of HBSD in the period of 1955-89 and analyzes the societal background of the change.

Two contiguous prefectures, Yamagata and Niigata, in the centre of the snowy area of Japan were taken as case study areas. Over 2000 cases of HBSD reported in local newspapers of each prefecture, the Yamagatashinbun and the Niigata-nippo, were recorded as sample data.

Some types of HBSD were found to increase with time. These were falls from a roof (RF), accidents caused by snow or ice fallen from a roof or an artificial object (FS), traffic accidents related to snow or ice (TA), accidents caused by snow removal equipment (SR) and falls into waterways (WF). HBSDs decreasing in time included damage caused by avalanches (AV) and destruction or breakage of buildings by snow load or impact force.

The social backgrounds of the transformation of HBSD were discussed and summarized as follows. Increases of TA were undoubtedly related to very rapid extension of motorization in Japan. Both physical and subjective factors, namely, changes in environments of houses and residential areas, and changes in characteristics of inhabitants, such as reduction of family size, depopulation and ageing, were main causes of increase in $\mathrm{RF}$ and FS. Increasing mechanized snow removal and man-machine interface problems caused by the spread of snow removal equipment into home use accelerated increases of SR. Some time-series tendency shown in other types of snow damage can be explained similarly from the viewpoint of changing social conditions.

In conclusion, snow damage which becomes the crucial issue in some fields in future might be predicted, and implications for countermeasures are discussed.

\section{Snow removal and de-icing using long flexible heat pipes}

\author{
M. SHIRAISHI, \\ Mechanical Engineering Laboratory, MITI, Namiki 1-2, Tsukuba, Ibaraki 305, Japan \\ M. Mochizuki, S. Sugihara, \\ Fujikura Ltd, Kiba 1-5, Koto-ku, Tokyo 135, Japan \\ Y. YAMAGishi AND F. WATANABE \\ Takemura Manufacturing Co., Ltd, Kojima 127, Nagano 380, Japan
}

\section{SUMMARY}

This paper presents methods newly developed in Japan for snow melting and de-icing, using a long flexible corrugated heat pipe. Use of these methods is rapidly expanding.
Poles for telephone or power lines in snowy areas in Japan have frequently been damaged by winter snow. Heavy snowfall imposes a settlement force on poles and a tension force on support wires. To prevent snow damage to the poles, a flexible corrugated heat pipe, $4 \mathrm{~m}$ in length and $26.5 \mathrm{~mm}$ in diameter is buried about $2 \mathrm{~m}$ into the 